\title{
An Efficient Active and Reactive Power Control of DFIG for a Wind Power Generator
}

\author{
Sabah Louarem \\ Department of Electrical Engineering, \\ Laboratory DAC HR, \\ Ferhat Abbas University Setif 1, Algeria \\ slouarem@univ-setif.dz \\ Tarek Bouktir \\ Department of Electrical Engineering, \\ Ferhat Abbas University Setif 1 , \\ Algeria \\ tbouktir@univ-setif.dz
}

\author{
Djamel Eddine Chouaib Belkhiat \\ Department of Physics, \\ Laboratory DAC HR, \\ Ferhat Abbas University Setif 1, Algeria \\ djamel.belkhait@univ-setif.dz \\ Saad Belkhiat \\ Department of Electrical Engineering, \\ Laboratory DAC HR, \\ Ferhat Abbas University Setif 1, Algeria \\ sbelkhiat@univ-setif.dz
}

\begin{abstract}
During the last decade, wind energy gained much importance as an energy source in power systems. DFIG energy is one of the most widely accepted types of renewable energy generation because of its several benefits. This paper presents a comparative study on the performance of different control strategies for DFIG wind turbines: proportional-integral (PI), Artificial Neural Networks (ANN), $\mathrm{H}_{\infty}$, and adaptive Fuzzy PI controller. Simulation results show that DFIG's performance, dynamic response, and robustness against machine parameter variations are improved with $\mathbf{H}_{\infty}$ control technique.
\end{abstract}

Keywords-wind energy; DFIG; PI controller; ANN controller; $H_{\infty}$ controller; adaptive fuzzy $P I$ controller

\section{INTRODUCTION}

In the last few years, severe environmental problems attracted the world's attention to renewable energy utilization [1]. Renewable energy sources, safe and reliable for the environment, are locally available energy sources [2]. Among them, wind power has received considerable attention [3]. Wind energy conversion systems (WECS) can be classified in two categories: variable and fixed-speed WECS. Among these techniques, variable speed wind generators are frequently used compared to fixed-speed systems because of their efficient energy production, improved power quality and dynamic performance during grid faults [4]. In this context, the doublyfed induction generator (DFIG) has proved its worth as a powerful solution to improve the power rating of wind [4-5].

Several control algorithms have been proposed to improve DFIG-based wind turbine system's behavior during normal operation [6]. Most of these control laws were generally based on the vector control concept. For instance, decoupled control of active and reactive power in a DFIG-based wind energy conversion system with conventional PI controllers has been proposed in [7]. The main disadvantage of this kind of controllers is that they require accurate knowledge of machine's parameters [8]. To address this issue, several studies focused on advanced and robust controllers have been conducted. For example, Predictive Functional Control (PFC) [9] was proposed in order to reduce the incidence of machine's parameter variations. In the same context, a predictive power controller synthesized by using a linearized state-space model of DFIG has been proposed in [10]. The design of an Adaptive Fuzzy Gain Scheduling of Proportional Integral controller (AFGPI) has been performed in [11] to address the issue of parameter changes and satisfactory power response was obtained, compared to the conventional PI controller. A neuronal controller has been designed in [12] to control the rotor currents of DFIG. The robustness of the proposed controller has been tested when the stator and the rotor selfinductances increased by $20 \%$.

Another robust $\mathrm{H}_{\infty}$ control design, based on a vector control strategy, has been carried out in [13] for the purpose of controlling active and reactive power flow between DFIG and the grid. The tracking control performance of the proposed controller was evaluated by modifying the machine's parameters. The obtained simulation results were satisfactory, showing the robustness of the $\mathrm{H}_{\infty}$ compared to the conventional PI controller. Recently, a robust power command based on the Active Disturbance Rejection Control (ADRC) for DFIG used in a WECS system has been designed in [14]. Simulation results showed that the proposed ADRC controller had the best performance in terms of robustness against machine's parameter variations. In the DFIGs, the stator is directly connected to the grid and the rotor is connected to the grid via the machine's and grid's inverters.

In this paper, a comparative study of four kinds of controllers (PI, ANN, $\mathrm{H}_{\infty}$ and adaptive fuzzy PI controllers) is performed for the purpose of driving the power flowing between the stator of the DFIG and the grid. 


\section{MODELING OF THE WIND TURBINE CONVERSION SYSTEM}

The diagram of the DFIG-based wind turbine is shown in Figure 1, where RSC and GSC are respectively the rotor side converter and the grid side converter.

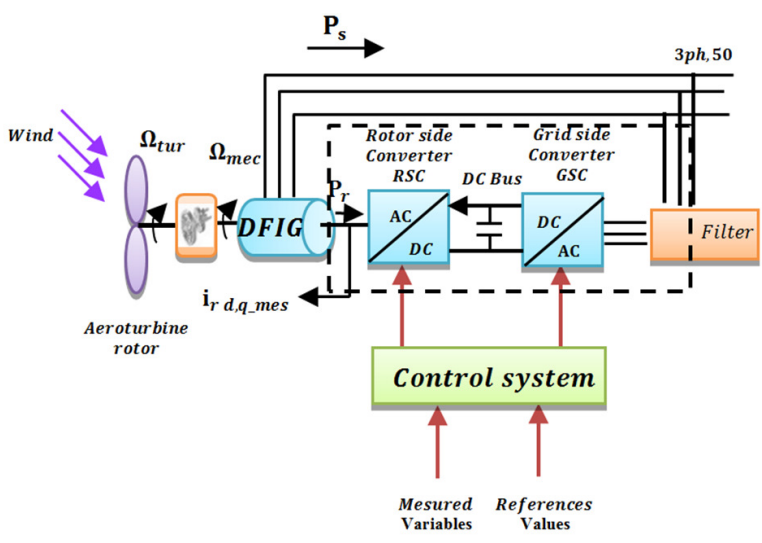

Fig. 1. Basic configuration of a DFIG wind turbine

\section{A. Wind Turbine Model}

The fraction of power extracted from the wind by a wind turbine is usually referred by the symbol $C_{p}$, which stands for the coefficient of performance or power coefficient. The actual mechanical power output $P_{m}$ of a wind turbine is given as [1516]:

$$
P_{m}=\frac{1}{2} \cdot \rho \cdot \pi \cdot R^{2} C_{p}(\lambda, \beta) v_{\text {wind }}^{3}
$$

where, $P_{m}$ is the mechanical output power of the turbine $[W]$, $\rho$ is the air density $\left[\mathrm{Kg} / \mathrm{m}^{3}\right], R$ is the rotor radius $[\mathrm{m}]$, and $\beta$ is the blade pitch angle $[\mathrm{deg}]$.

The power coefficient expresses the rotor aerodynamics as a function of both tip speed ratio $\lambda$ and pitch angle of the rotor blades $\beta$. The tip speed ratio is defined as the ratio between the blade tip speed and the wind speed, expressed as [17]:

$$
\lambda=\frac{\omega R}{v_{\text {wind }}}
$$

where $\omega$ is the rotor speed $[\mathrm{rad}]$ and $v_{\text {wind }}$ is the wind speed $[m / s]$.

In order to determine $C_{p}$, the following generic equation is used [18-19]:

$$
\begin{aligned}
C_{p}= & (0.5-0.0167 \cdot(\beta-2)) \cdot \sin \left[\frac{\pi \cdot(\lambda+0.1)}{18.5-0.3(\beta-2)}\right]- \\
& 0.00184 .(\lambda-3) \cdot(\beta-2)
\end{aligned}
$$

\section{B. Modeling of the Doubly-Fed Induction Generator}

Concordia and Park's transformation will be applied to the three-phase model of the IG. Dynamic voltages equations in an arbitrary $d-q$ reference frame are following [20-21]. The stator voltage equations are:

$$
\begin{aligned}
& V_{s d}=R_{s} I_{s d}+\frac{d}{d t}\left(\varphi_{s d}\right)-\omega_{s} \varphi_{s q} \\
& V_{s q}=R_{s} I_{s q}+\frac{d}{d t}\left(\varphi_{s q}\right)-\omega_{s} \varphi_{s d}
\end{aligned}
$$

The rotor voltage equations are

$$
\left\{\begin{array}{l}
V_{r d}=R_{r} I_{r d}+\frac{d}{d t}\left(\varphi_{r d}\right)-\left(\omega_{s}-\omega_{r}\right) \varphi_{r q} \\
V_{r q}=R_{r} I_{r d}+\frac{d}{d t}\left(\varphi_{r q}\right)-\left(\omega_{s}-\omega_{r}\right) \varphi_{r d}
\end{array}\right.
$$

The stator current of DFIG was decomposed into active and reactive component via the coordinate transformation and the field-oriented vector transformation. In order to regulate the power of the DFIG based wind turbine system, the vector control strategy is used. It consists of using the flux orientation, such as stator flux orientation (SFO) [7-22]: $V_{s d}=0$ and $V_{s q}=V_{s}=\omega_{s} \varphi_{s}$. The active and reactive powers at the stator side and rotor side of the DFIG are given as:

$$
\begin{aligned}
& \left\{\begin{array}{c}
P_{s}=-V_{s} \frac{L_{m}}{L_{s}} I_{r q} \\
Q_{s}=\frac{V_{S} \psi_{s}}{L_{S}}-\frac{V_{s} L_{m}}{L_{s}} I_{r d}
\end{array}\right. \\
& \left\{\begin{aligned}
V_{r d}= & R_{r} \cdot I_{r d}+\left(L_{r}-\frac{L_{m}^{2}}{L_{s}}\right) \frac{d I_{r d}}{d t}- \\
& g \omega_{s}\left(L_{r}-\frac{L_{m}^{2}}{L_{s}}\right) I_{r q} \\
V_{r q}= & R_{r} \cdot I_{r q}+\left(L_{r}-\frac{L_{m}^{2}}{L_{s}}\right) \frac{d I_{r q}}{d t}+ \\
& g \omega_{s}\left(L_{r}-\frac{L_{m}^{2}}{L_{s}}\right) I_{r d}+g \omega_{s} \frac{L_{m} \cdot \varphi_{s}}{L_{s}}
\end{aligned}\right.
\end{aligned}
$$

In steady state, the second derivative terms in (7) are neglected and the third term constitutes cross-coupling tams.

$$
\left\{\begin{array}{c}
V_{r d}=R_{r} \cdot I_{r d}-g \omega_{s}\left(L_{r}-\frac{L_{m}^{2}}{L_{s}}\right) I_{r q} \\
V_{r q}=R_{r} \cdot I_{r q}+g \omega_{s}\left(L_{r}-\frac{L_{m}^{2}}{L_{s}}\right) I_{r d}+g \omega_{s} \frac{L_{m} \cdot \varphi_{s}}{L_{s}}
\end{array}\right.
$$

\section{CONTROLLER SYNTHESIS}

\section{A. PI Controller Synthesis}

Figure 2 shows the block diagram of the system controlled with the PI controller. The terms $K_{p}$ and $K_{i}$ represent the proportional and integral gain respectively. The ratio $B / A$ represents the transfer function to be controlled, where $A$ and $B$ are presently defined as follows:

$$
A=L_{s} R_{r}+p L_{s}\left(L_{r}-\frac{L_{m}^{2}}{L_{s}}\right) \text { and } B=-L_{m} V_{s}
$$

The response time of the controlled system will be fixed to $10 \mathrm{~ms}$. This value is sufficient for our application, while a lower value could involve transients with important overshoots. The calculated terms are given in [7-23].

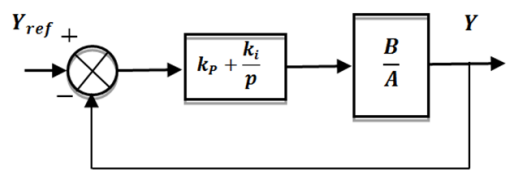

Fig. 2. System with PI controller

The transfer function of the open loop becomes:

$$
G(p)=-\frac{k_{p} \frac{L_{m} V_{s}}{\left(L_{r} L_{s}-L_{m}^{2}\right)}}{\mathrm{p}}
$$


The transfer function of the closed loop is expressed by:

$$
H(p)=\frac{1}{1+\mathrm{p} \tau_{r}}
$$

where $\tau_{r}$ is the response time.

Now, we express the controller gains correction based on the settings of the machines and the response time as follows:

$$
\left\{\begin{array}{c}
k_{p}=-\frac{1}{\tau_{r}} \frac{L_{s}\left(L_{r}-\frac{L_{m}^{2}}{L_{s}}\right)}{L_{m} V_{s}} \\
k_{i}=-\frac{1}{\tau_{r}} \frac{R_{r} L_{s}}{L_{m} V_{s}}
\end{array}\right.
$$

\section{B. ANN Controller Synthesis}

ANN models are inspired from the basic framework of the brain [24-25]. In this study, the ANN controller was performed by using the nftool of Matlab. The DFIG-based wind turbine is simulated with the PI controller. The data, before and after the controller are computed and saved. After that, the network training was done for 10 iterations. The hidden layers contained 40 neurons.

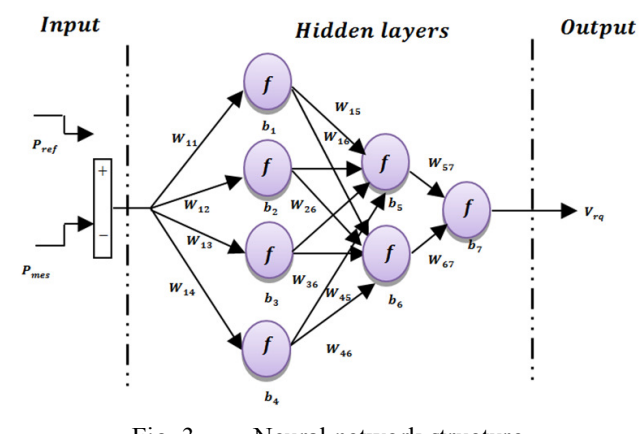

Fig. 3. Neural network structure

\section{Design of the $H_{\infty}$ Controller}

In this section, we present the $H_{\infty}$ mixed-sensitivity synthesis method for robust tracking control design. The main idea consists of synthesizing the controller by minimizing $H_{\infty}$ 's performance. As mentioned above, the quotient $B / A$ represents the transfer function to be controlled. Thus, we can define the tracking error, the input control and the output as:

$$
\begin{aligned}
& e(s)=S(s) Y r e f(s) \\
& u(s)=K(s) S(s) Y r e f(s) \\
& Y(s)=T(s) \operatorname{Yref}(s)
\end{aligned}
$$

where $S(s)=\left(I+\frac{B(s)}{A(s)} K(s)\right)^{-1}$ is the sensitivity function and $T(s)=\frac{B(s)}{A(s)} K(s)\left(I+\frac{B(s)}{A(s)} K(s)\right)^{-1}$ is the closed-loop transfer function. We are interested in designing the controller $K(s)$. For that, we will consider the $H_{\infty}$ mixed-sensitivity design problem illustrated in Figure 4, where, $W_{1}(s)$ and $W_{2}(s)$ are selected as loop-shaping weights. Hence, the tracking control design is considered as an optimization problem which consists of finding a stabilizing controller $K(s)$ to minimize the following cost function:

$$
\left\|\left[\begin{array}{c}
W_{1}(s) S(s) \\
W_{2}(s) K(s) S(s)
\end{array}\right]\right\|_{\infty}
$$

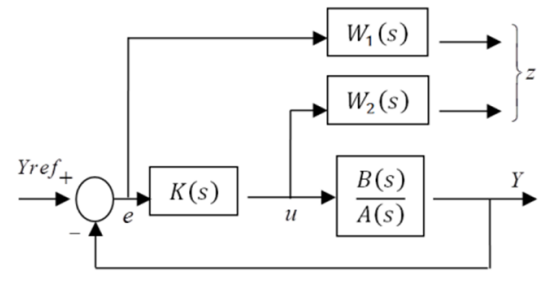

Fig. 4. $\quad S / K S$ mixed-sensitivity minimization

The design weights $W_{1}(s)$ and $W_{2}(s)$ were selected as:

$$
\begin{aligned}
& W_{1}(s)=\frac{6000}{s+30} \\
& W_{2}(s)=\frac{0.0025 s^{2}}{0.0005 s^{2}+5 s+100}
\end{aligned}
$$

By using the robust control toolbox of Matlab, we obtain the following controller:

$$
K(s)=\frac{-2.98 \times 10^{4} s^{3}-3.00 \times 10^{8} s^{2}-2.7 \times 10^{10} s-4.20 \times 10^{11}}{s^{4}+1.25 \times 10^{6} s^{3}+1.23 \times 10^{10} s^{2}+6.19 \times 10^{11} s+7.34 \times 10^{12}}
$$

\section{Adaptive Fuzzy PI Controller Synthesis}

The adaptive fuzzy $P I$ controller scheme is given in Figure 5. The FLS inputs are the errors (e) in active, reactive, and rate of change in active and reactive power error $(d e)$. The output of the fuzzy controller is $d u$. In contrast to the controller where controller parameters ( $k_{p}$ and $k_{i}$ gains) are tuned in a predefined way [30], FLS is used to tune the $k_{p}$ and $k_{i}$ parameters of the PI so that the controller can keep up with parametric changes and reference signals can be tracked.

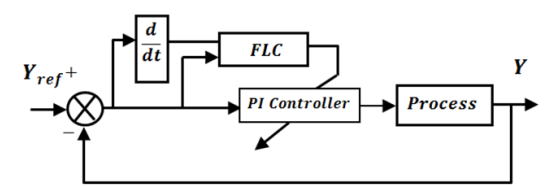

Fig. 5. PI control system with fuzzy gain adapter

The fuzzy sets are defined as: NB is Negative Big, NM is Negative Medium, NS is Negative Small, ZR is Zero, PS is Positive Small, PM is Positive Medium, PB is Positive Big, B is Big and $\mathrm{S}$ is small. The max-min reasoning method and the center of gravity defuzzification method are used [31]. The values of $K_{p}^{\prime}$ and $K_{i}^{\prime}$ are determined by a set of fuzzy rules of the form designed fuzzy gain scheduling controller has two inputs and two outputs.

$$
\begin{aligned}
K_{p}^{\prime} & =\frac{K_{p}-K_{p \min }}{K_{\text {pmax }}-K_{p \min }} \\
K_{i}^{\prime} & =\frac{K_{i}-K_{\text {imin }}}{K_{\text {imax }}-K_{\text {imin }}}
\end{aligned}
$$

\section{SimUlation RESULTS}

Comparative simulations of the controllers were performed in Matlab. The proposed control algorithm's nominal parameters are indicated in the Appendix. It was first tested in ideal mode and driven to 1500rpm. The different controllers 
were tested and compared by two different criteria, namely reference tracking performance, and robustness by varying the system parameters.

\section{A. Reference Tracking in Ideal Conditions Mode}

Simulation results of active and reactive power using the classical PI controller, an ANN controller, the proposed $\mathrm{H}_{\infty}$ controller and the proposed adaptive fuzzy PI controller are shown in Figure 6. As expected, both active and reactive powers have been produced with good accuracy. Moreover, they can track the desired reference after a finite time interval and the answers are without overshoots for different controllers.
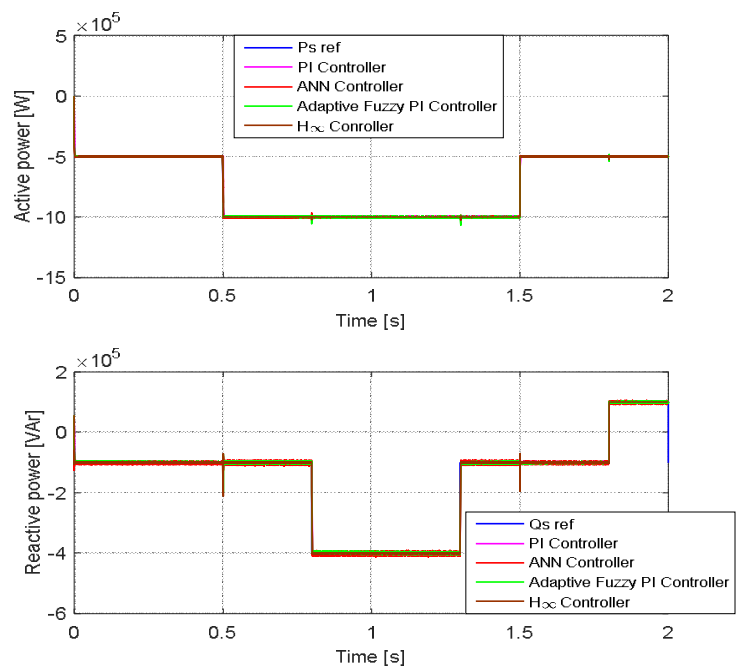

Fig. 6. Active and reactive power behavior
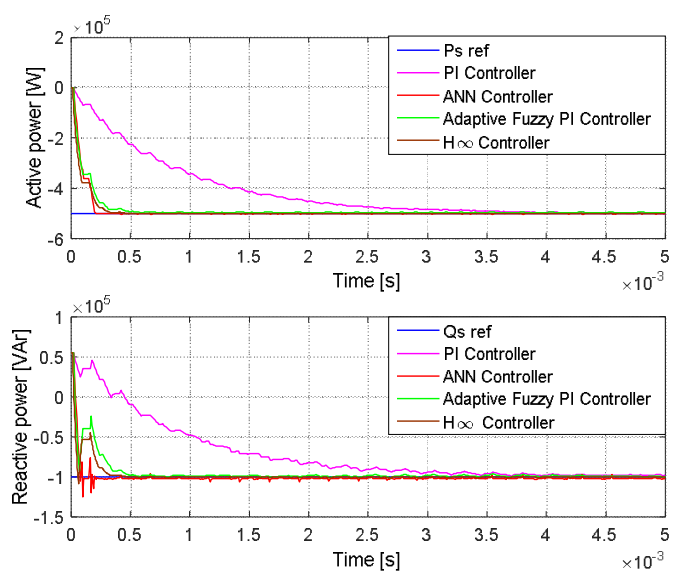

Fig. 7. Zoom in active and reactive power behavior

Figure 7 shows a zoom view of active and reactive power behavior from 0 to $0.005 \mathrm{~s}$ to compare the response times of all controllers. We can notice a quicker response time for ANN and $\mathrm{H}_{\infty}$ controllers. In the same context, we notice that the system controlled by the PI controller evolved to a steady state with an important response time in comparison with the other controllers.
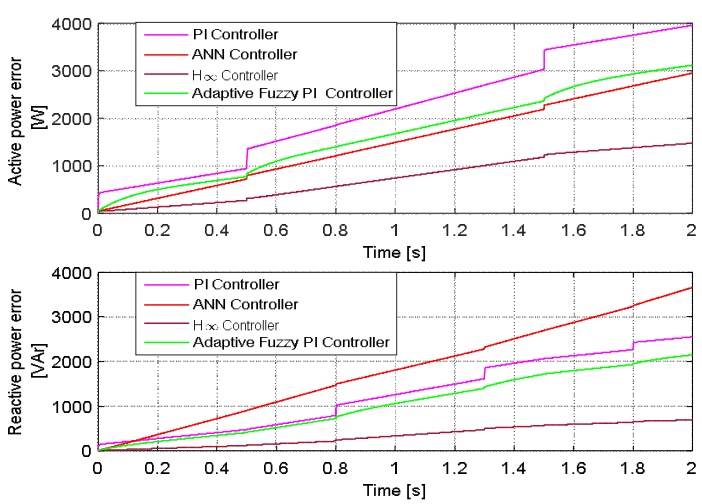

Fig. 8. Evolution of cumulative tracking error functions

In order to show which controller has the best steady state accuracy, we graph the evolution of the following cumulative tracking error functions:

$$
\begin{array}{ll}
C T E_{P}=\int_{0}^{t}\left|P_{s}-P_{\text {sref }}\right| d t, & t \in\left[\begin{array}{ll}
0 & 2 s
\end{array}\right] \\
C T E_{Q}=\int_{0}^{t}\left|Q_{s}-Q_{\text {sref }}\right| d t, & t \in\left[\begin{array}{ll}
0 & 2 s
\end{array}\right]
\end{array}
$$

As shown in Figure 8, the $\mathrm{H}_{\infty}$ controller has the best steady state accuracy in comparison with the other controllers. In contrast to the $\mathrm{H}_{\infty}$ controller, the conventional PI controller has low steady state accuracy.

\section{B. Robustnes}

We are interested in evaluating the robustness of the different controllers against parameter variation for parameters such as the inductances $L_{s}, L_{r}$, the mutual inductance $L_{m}$ and the resistance $R_{r}$. The controllers' performances are compared according to rise time, maximum peak overshoot and settling time. We test the robustness of the controllers against mutual inductance variations. Figure 9 and Table I present the simulation results for a parametric variation in the order of $-10 \%$. Unlike the adaptive fuzzy PI controller and the $\mathrm{H}_{\infty}$ controller, we can remark that the ANN and PI controllers lose their performance regarding maximum overshoot.
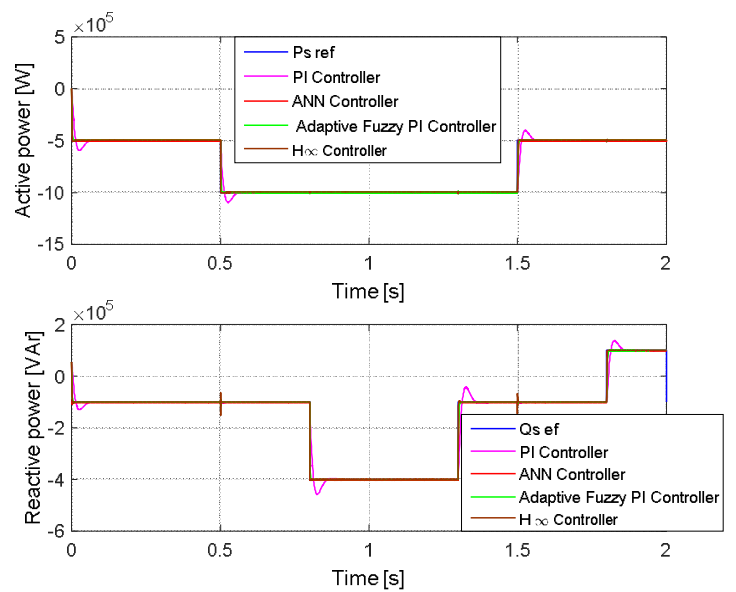

Fig. 9. Active and reactive power behavior with $-10 \%$ mutual inductance variation 
TABLE I. COMPARISON OF THE RESPONSE PARAMETERS $\left(L_{m}-10 \%\right)$

\begin{tabular}{|c|c|c|c|}
\hline \multicolumn{5}{|c|}{ Active power } \\
\hline Controller & $\begin{array}{c}\text { Rise time } \\
\text { (s) }\end{array}$ & $\begin{array}{c}\text { Maximum } \\
\text { overshoot (\%) }\end{array}$ & $\begin{array}{c}\text { Settling } \\
\text { time (s) }\end{array}$ \\
\hline PI & 0.0102 & 29.43 & 0.0541 \\
\hline ANN & 0.0018 & 7.62 & 0.0023 \\
\hline H $_{\infty}$ & 0.0023 & 0.77 & 0.001 \\
\hline Adaptive Fuzzy PI & 0.0024 & 0.01 & 0.0042 \\
\hline \multicolumn{4}{|c|}{ Reactive power } \\
\hline PI & 0.0102 & 19.20 & 0.0252 \\
\hline ANN & 0.0005 & 7.62 & 0.0021 \\
\hline H $_{\infty}$ & 0.0005 & 1.20 & 0.0010 \\
\hline Adaptive Fuzzy PI & 0.0024 & 0.14 & 0.0042 \\
\hline
\end{tabular}

In order to refine our study, we tested the robustness of the proposed controllers against a mutual inductance variation in the order of $-25 \%$. The simulation results are presented in Figure 10 and Table II. We can note that the PI and ANN controllers lose their performance in response time with undesirable maximum overshoots and only adaptive fuzzy PI controller and $\mathrm{H}_{\infty}$ controller can resist this parametric variation with a slight superiority for $\mathrm{H}_{\infty}$ controller in terms of response time.
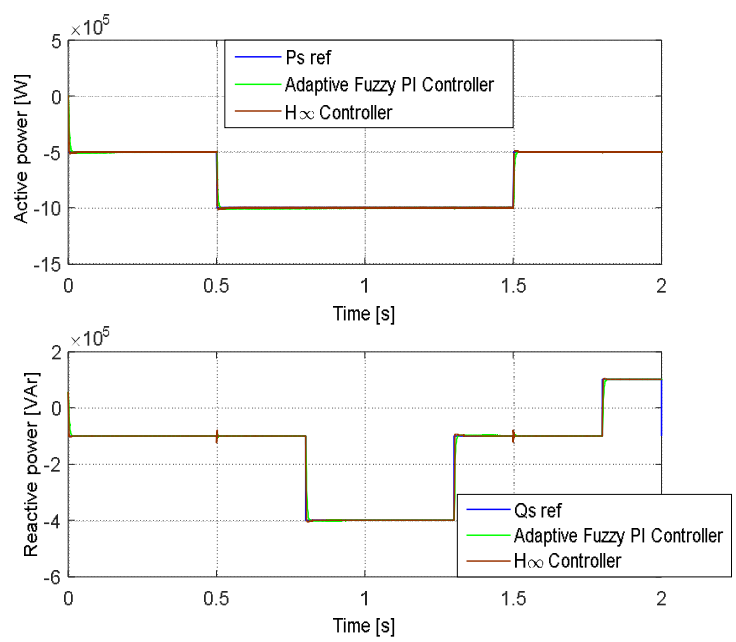

Fig. 10. Active and reactive power behavior using $\mathrm{H}_{\infty}$ and adaptive fuzzy PI controllers with $-25 \%$ mutual inductance variation

TABLE II. COMPARISON OF THE RESPONSE PARAMETERS $\left(L_{m}-25 \%\right)$

\begin{tabular}{|c|c|c|c|}
\hline Controller & $\begin{array}{c}\text { Rise } \\
\text { time (s) }\end{array}$ & $\begin{array}{c}\text { Maximum } \\
\text { overshoot (\%) }\end{array}$ & $\begin{array}{c}\text { Settling } \\
\text { time (s) }\end{array}$ \\
\hline \multicolumn{4}{|c|}{ Active power } \\
\hline $\mathbf{H}_{\infty}$ & 0.0014 & 1.95 & 0.0057 \\
\hline Adaptive Fuzzy PI & 0.0060 & 0.61 & 0.0104 \\
\hline \multicolumn{4}{|c|}{ Reactive power } \\
\hline $\mathbf{H}_{\infty}$ & 0.0015 & 2.96 & 0.0058 \\
\hline Adaptive Fuzzy PI & 0.0060 & 0.70 & 0.0106 \\
\hline
\end{tabular}

In the same way, the robustness of the proposed controllers against rotor inductance variations was tested. Two deep simulations have been performed (Figures 11 and 12). The first one concerns a variation in the order of $+10 \%$ and the second a variation in the order of $+25 \%$. The results are shown in Tables
III and IV respectively. Note that only two controllers have resisted the second test with slight superiority regarding response time for the $\mathrm{H}_{\infty}$ controller. Regarding stator inductance variations, the simulation results are shown in Tables V and VI. As in the preceding cases, only the $\mathrm{H}_{\infty}$ and the adaptive fuzzy PI controllers can resist the high stator inductance variation.
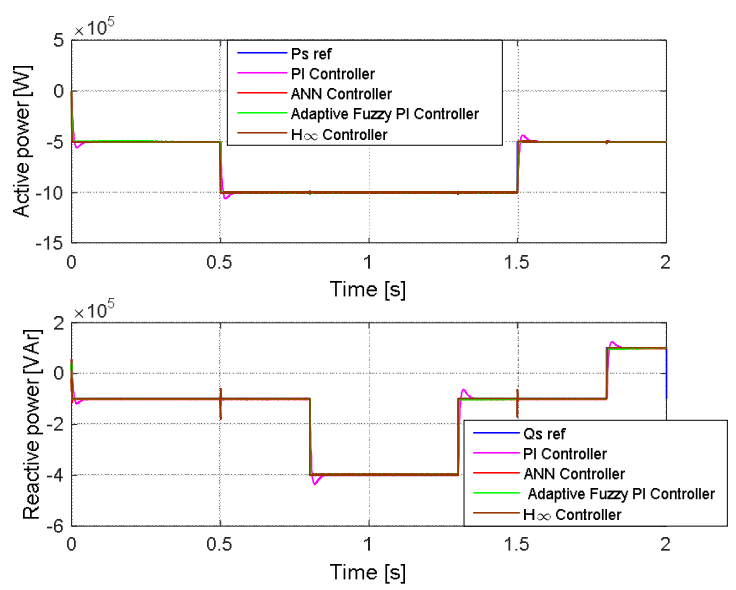

Fig. 11. Active and reactive power behavior with $10 \%$ rotor inductance variation

TABLE III. COMPARISON OF THE RESPONSE PARAMETERS

$$
\left(L_{r}+10 \%\right)
$$

\begin{tabular}{|c|c|c|c|}
\hline \multicolumn{4}{|c|}{ Active power } \\
\hline Controller & $\begin{array}{c}\text { Rise time } \\
\text { (s) }\end{array}$ & $\begin{array}{c}\text { Maximum } \\
\text { overshoot (\%) }\end{array}$ & $\begin{array}{c}\text { Settling } \\
\text { time (s) }\end{array}$ \\
\hline PI & 0.0066 & 11.94 & 0.0414 \\
\hline ANN & 0.0011 & 0.37 & 0.0012 \\
\hline $\mathbf{H}_{\infty}$ & 0.0003 & 0.40 & 0.0005 \\
\hline Adaptive Fuzzy PI & 0.0013 & 0.0023 \\
\hline \multicolumn{4}{|c|}{ Reactive power } \\
\hline PI & 0.0060 & 17.76 & 0.0427 \\
\hline ANN & 0.0003 & 17.16 & 0.0013 \\
\hline $\mathbf{H}_{\infty}$ & 0.0003 & 0.78 & 0.0005 \\
\hline Adaptive Fuzzy PI & 0.0013 & 0.25 & 0.0024 \\
\hline
\end{tabular}
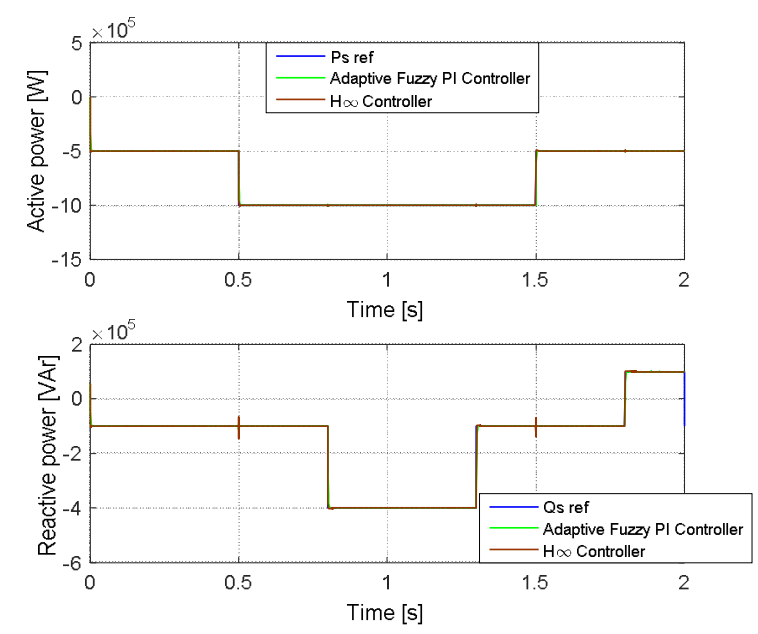

Fig. 12. Active and reactive power behavior using $\mathrm{H}_{\infty}$ and adaptive fuzzy PI controllers with $+25 \%$ rotor inductance variation 
TABLE IV. COMPARISON OF THE RESPONSE PARAMETERS $\left(L_{r}+25 \%\right)$

\begin{tabular}{|c|c|c|c|}
\hline Controller & $\begin{array}{c}\text { Rise } \\
\text { time (s) }\end{array}$ & $\begin{array}{c}\text { Maximum } \\
\text { overshoot (\%) }\end{array}$ & $\begin{array}{c}\text { Settling } \\
\text { time (s) }\end{array}$ \\
\hline \multicolumn{4}{|c|}{ Active power } \\
\hline $\mathbf{H}_{\infty}$ & 0.0007 & 0.93 & 0.0011 \\
\hline Adaptive Fuzzy PI & 0.0028 & 0.31 & 0.0106 \\
\hline \multicolumn{4}{|c|}{ Reactive power } \\
\hline $\mathbf{H}_{\infty}$ & 0.0007 & 1.54 & 0.0038 \\
\hline Adaptive Fuzzy PI & 0.0028 & 0.18 & 0.0011 \\
\hline
\end{tabular}
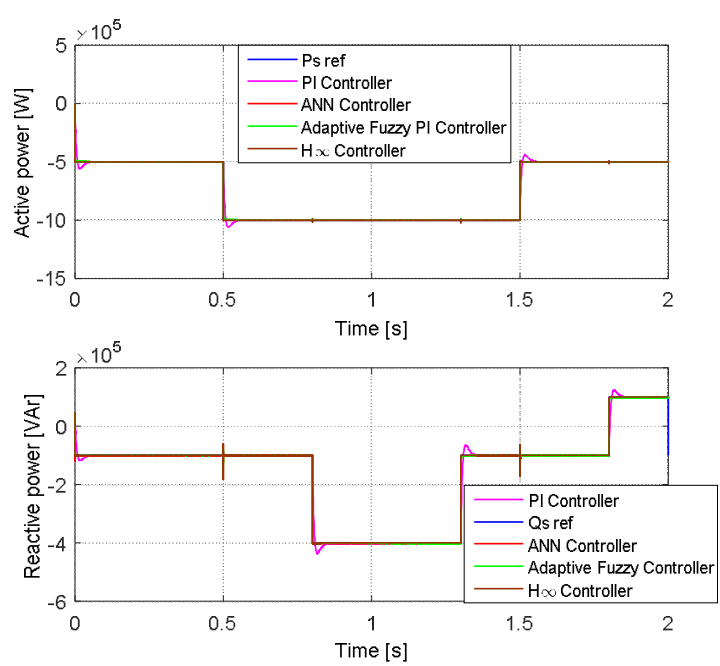

Fig. 13. Active and reactive power behavior using the four controllers with $+10 \%$ variation of $L_{s}$

TABLE V. COMPARISON OF THE RESPONSE PARAMETERS $\left(L_{s}+10 \%\right)$

\begin{tabular}{|c|c|c|c|}
\hline \multicolumn{4}{|c|}{ Active power } \\
\hline Controller & $\begin{array}{c}\text { Rise time } \\
\text { (s) }\end{array}$ & $\begin{array}{c}\text { Maximum } \\
\text { overshoot (\%) }\end{array}$ & $\begin{array}{c}\text { Settling } \\
\text { time (s) }\end{array}$ \\
\hline PI & 0.0066 & 11.51 & 0.0411 \\
\hline ANN & 0.0010 & 0.36 & 0.0012 \\
\hline $\mathbf{H}_{\infty}$ & 0.0003 & 0.39 & 0.0005 \\
\hline Adaptive Fuzzy PI & 0.0024 & 0.01 & 0.0042 \\
\hline \multicolumn{5}{|c|}{ Reactive power } \\
\hline PI & 0.0068 & 17.11 & 0.0424 \\
\hline ANN & 0.0003 & 18.86 & 0.0012 \\
\hline $\mathbf{H}_{\infty}$ & 0.0003 & 0.74 & 0.0005 \\
\hline Adaptive Fuzzy PI & 0.0013 & $/$ & 0.0023 \\
\hline
\end{tabular}

TABLE VI. COMPARISON OF THE RESPONSE PARAMETERS $\left(L_{s}+25 \%\right)$

\begin{tabular}{|c|c|c|c|}
\hline Controller & $\begin{array}{c}\text { Rise } \\
\text { time (s) }\end{array}$ & $\begin{array}{c}\text { Maximum } \\
\text { overshoot (\%) }\end{array}$ & $\begin{array}{c}\text { Settling } \\
\text { time (s) }\end{array}$ \\
\hline \multicolumn{4}{|c|}{ Active power } \\
\hline $\mathbf{H}_{\infty}$ & 0.0007 & 0.90 & 0.0011 \\
\hline Adaptive Fuzzy PI & 0.0028 & 0.01 & 0.0049 \\
\hline \multicolumn{4}{|c|}{ Reactive power } \\
\hline $\mathbf{H}_{\infty}$ & 0.0007 & 1.30 & 0.0011 \\
\hline Adaptive Fuzzy PI & 0.0003 & 1.80 & 0.0052 \\
\hline
\end{tabular}

Finally, regarding the rotor resistance variation, which is the result of the rotor heating, a deep simulation was performed by considering a rotor resistance variation in the order of $100 \%$. The simulation results are shown in Figure 15 and the controllers' performances are summarized in Table VII. Thus, we can see that the different controllers can drive the system to track the reference signals. In other words, the active and reactive powers follow correctly the reference signals.
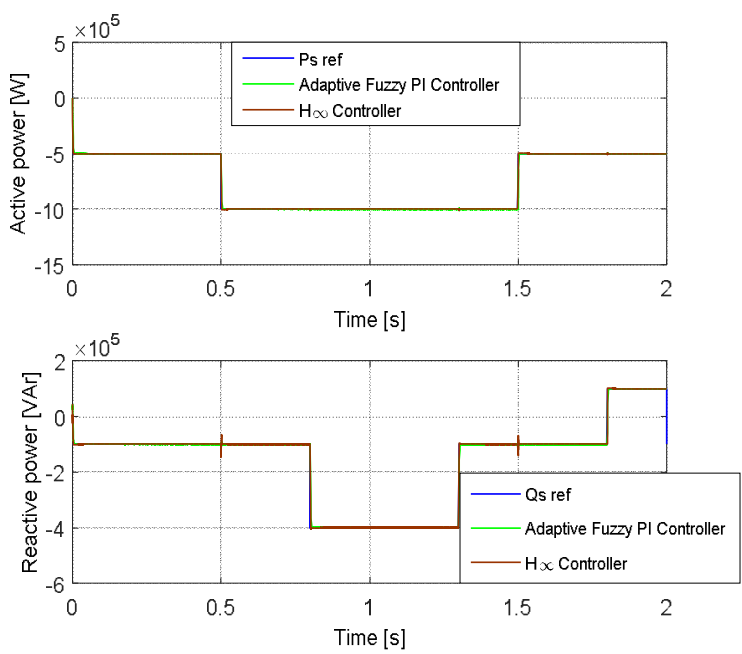

Fig. 14. Active and reactive power behavior using the $\mathrm{H}_{\infty}$ and adaptive fuzzy PI controller with $+25 \%$ variation of $L_{S}$.

TABLE VII. COMPARISON OF THE RESPONSE PARAMETERS $\left(R_{r}+100 \%\right)$

\begin{tabular}{|c|c|c|c|}
\hline \multicolumn{5}{|c|}{ Active power } \\
\hline Controller & $\begin{array}{c}\text { Rise time } \\
\text { (s) }\end{array}$ & $\begin{array}{c}\text { Maximum } \\
\text { overshoot (\%) }\end{array}$ & $\begin{array}{c}\text { Settling } \\
\text { time (s) }\end{array}$ \\
\hline PI & 0.00220 & 1.17 & 0.02330 \\
\hline ANN & 0.00020 & 0.10 & 0.00020 \\
\hline H $_{\infty}$ & 0.00003 & 0.39 & 0.00007 \\
\hline Adaptive Fuzzy PI & 0.0002 & $/$ & 0.00050 \\
\hline \multicolumn{5}{|c|}{ Reactive power } \\
\hline PI & 0.00240 & 5.15 & 0.1500 \\
\hline ANN & 0.00005 & 24.37 & 0.1498 \\
\hline H $_{\infty}$ & 0.00001 & 71.37 & 0.1499 \\
\hline Adaptive Fuzzy PI & 0.00004 & 3.01 & 0.1500 \\
\hline
\end{tabular}

As far as the active power is concerned, it is clear that the $\mathrm{H}_{\infty}$ controller has the best rise time and settling time when compared with the other controllers. However, concerning reactive power, the controller performances are almost identical to those of the ANN controller with a slight superiority for $\mathrm{H}_{\infty}$ controller. In a nutshell, the simulation results presented in this work have shown that the $\mathrm{H}_{\infty}$ controller has the best steady state accuracy compared with the other controllers. Regarding the robustness against parametric variation, the $\mathrm{H}_{\infty}$ and adaptive fuzzy PI controllers have the best tracking performance and robustness with a slight superiority of the $\mathrm{H}_{\infty}$ controller.

\section{CONCLUSION}

In this paper, the control of doubly fed induction generator (DFIG) based wind energy conversion has been studied. The DFIG's stator was directly connected to the grid and the rotor was connected to the grid via the machine's and grid's inverters. The design of four control strategies, namely PI, ANN, adaptive fuzzy $\mathrm{PI}$, and $\mathrm{H}_{\infty}$ controller, has been presented and discussed. The 
obtained results showed that the $\mathrm{H}_{\infty}$ controller is the best to drive the DFIG's stator and to track perfectly the active and reactive power references with very good tracking performance, namely low-rise time, low settling time, and high steady-state accuracy. The $\mathrm{H}_{\infty}$ controller seems more robust than all other controllers against parameter variations.
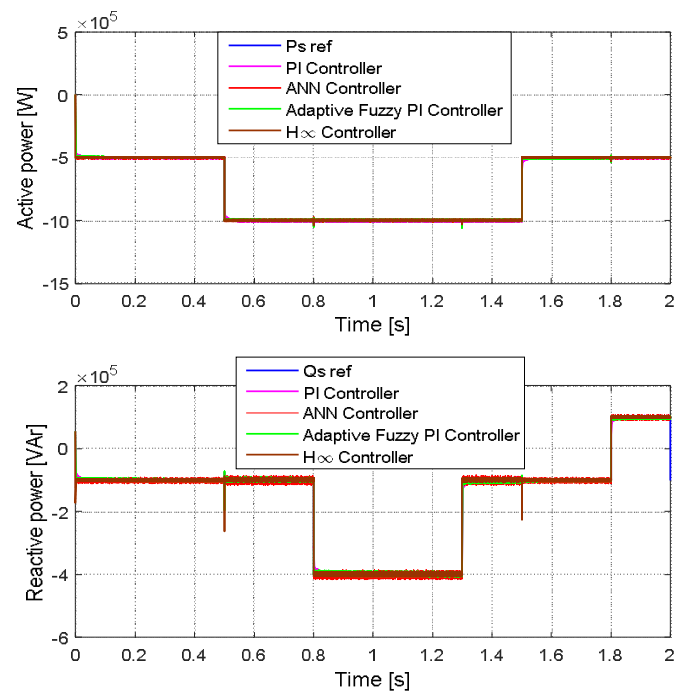

Fig. 15. Active and reactive power behavior using the four controllers with $+100 \%$ variation of $R_{r}$

APPENDIX

\begin{tabular}{|c|c|}
\hline \multicolumn{2}{|c|}{ Rating of the wind turbine } \\
\hline Power & $P=1.5 \mathrm{MW}$ \\
\hline Radius & $R=35.5 \mathrm{~m}$ \\
\hline Inertia & $J=1000 \mathrm{Kg} \cdot \mathrm{m}^{2}$ \\
\hline Gear box ratio & 90 \\
\hline Damping coefficient & $f=0.0024 \mathrm{Nm} \cdot \mathrm{rad}^{-1}$ \\
\hline \multicolumn{2}{|c|}{ Wound rotor induction machine } \\
\hline Power & $1.5 \mathrm{MW}$ \\
\hline Stator voltage & $V_{s}=398 / 690 \mathrm{~V}$ \\
\hline Rotor voltage & $V_{r}=225 \mathrm{~V}$ \\
\hline$p$ & 2 \\
\hline \multicolumn{2}{|c|}{ Wind turbine parameters } \\
\hline Blades radius & $R=35.25 \mathrm{~m}$ \\
\hline Gain of gearbox & $G=90$ \\
\hline Air density & $\rho=1.225 \mathrm{~kg} / \mathrm{m}^{3}$ \\
\hline
\end{tabular}

\section{REFERENCES}

[1] B. Yang, X. Zhang, T. Yu, H. Shu, Z. Fang, "Grouped grey wolf optimizer for maximum power point tracking ofdoubly-fed induction generator based wind turbine", Energy Conversion Management, Vol. 133, pp. 427-443, 2017

[2] S. V. Varzaneh, M. Abedi, G. B. Gharehpetian, "A new simplified model for assessment of power variation of DFIG-based wind farm participating in frequency control system", Electric Power Systems Research, Vol. 148, pp. 220-229, 2017

[3] D. K. V. Sagiraju, Y. P. Obulesu, S. B. Choppavarapu, "Dynamic performance improvement of standalone battery integrated PMSG wind energy system using proportional resonant controller", Engineering Science and Technology, an International Journal, Vol. 20, No. 4, pp. 1353-1365, 2017
[4] O. P. Bharti, R. K. Saket, S. K. Nagar, "Controller Design of DFIG Based Wind Turbine by Using Evolutionary Soft Computational Techniques", Engineering, Technology \& Applied Science Research Vol. 7, No. 3, pp. 1732-1736, 2017

[5] H. Nian, C. Cheng, Y. Song, "Coordinated Control of DFIG System based on Repetitive Control Strategy under Generalized Harmonic Grid Voltages", Journal of Power Electronics, Vol. 17, No. 3, pp. 733-743, 2017

[6] V. N. A. Duggirala, V. N. K. Gundavarapu, "Improved LVRT for grid connected DFIG using enhanced field oriented control technique with super capacitor as external energy storage system", Engineering Science and Technology, an International Journal, Vol. 19, pp. 1742-1752, 2016

[7] E. G. Shehata, "Sliding mode direct power control of RSC for DFIGs driven by variable speed wind turbines", Alexandria Engineering Journal, Vol. 54, No. 4, pp. 1067-1075, 2015

[8] F. Poitiers, T. Bouaouiche, M. Machmoum, "Advanced control of a doubly-fed induction generator for wind energy conversion”, Electric Power Systems Research, Vol. 79, pp. 1085-1096, 2009

[9] F. E. V. Taveiros, L. S. Barros, F. B. Costa, "Back-to-back converter state-feedback control of DFIG (doubly-fed induction generator)-based wind turbines", Energy, Vol. 89, pp. 896-906, 2015

[10] Z. Xin-fang, X. Da-ping, L. Yi-bing, "Predictive Functional Control of a Doubly FedInduction Generator for Variable Speed Wind Turbines", 5th World Congress on Intelligent Control and Automation, Hangzhou, China, June 15-19, 2004

[11] A. J. Sguarezi Filho, M. E. Oliveira Filho, E. Ruppert, “A Predictive Power Control for Wind Energy", North American Power Symposium 2010, Arlington, USA, September 26-28, 2010

[12] K. Bedoud, M. Ali-Rachedi, T. Bahi, R. Lakel, “Adaptive Fuzzy Gain Scheduling of PI Controller for control of the Wind Energy Conversion Systems", Energy Procedia, Vol. 74, pp. 211-225, 2015

[13] K. Bedoud, M. Ali-Rachedi, T. Bahi, R. Lakel, A. Grid, "Robust Control of Doubly Fed Induction Generator for Wind Turbine Under SubSynchronous Operation Mode", Energy Procedia, Vol. 74, pp. 886-899, 2015

[14] S. Abdelmalek, H. Belmili, "A New Robust $\mathrm{H}_{\infty}$ Control Power", in: Handbook of Research on Advanced Intelligent Control Engineering and Automation, IGI Global, 2015

[15] A. Boualouch, T. Nasser, A. Boukhriss, A. Frigui, "Robust Power Control of a DFIG used in Wind Turbine Conversion System", International Energy Journal, Vol. 17, No. 1, pp. 1-10, 2017

[16] S. Ebrahimkhani, "Robust fractional order sliding mode control of doubly-fed induction generator (DFIG)-based wind turbines", ISA Transactions, Vol. 63, pp. 343-3540, 2016

[17] A. Tapia, G. Tapia, J. X. Ostolaza, J. Ramon Saenz, "Modeling and Control of a Wind Turbine Driven Doubly Fed Induction Generator", IEEE Transactions On Energy Conversion, Vol. 18, No. 2, pp. 194-204, 2003

[18] L. M. Fernandez, C. A. Garcia, F. Jurado, "Comparative study on the performance of control systems for doubly fed induction generator (DFIG) wind turbines operating with power regulation", Energy, Vol. 33, pp. 1438-1452, 2008

[19] E. S. Abdin, W. Xu, "Control Design and Dynamic Performance Analysis of a Wind Turbine-Induction Generator Unit", IEEE Transactions On Energy Conversion, Vol. 15, No. 1, pp. 91-96, 2000

[20] S. El Aimani, Modelisation de Differents Technologies d'Eoliennes Intégrées Dans un Reseau de Moyenne Rension, PhD Thesis, Ecole Centrale de Lille, Universite des Sciences et Technologie de Lille, 2004 (in French)

[21] T. Ghennam, K. Aliouane, F. Akel, B. Francois, E. M. Berkouk, "Advanced control system of DFIG based wind generators for reactive power production and integration in a wind farm dispatching", Energy Conversion and Management, Vol. 105, pp. 240-250, 2015

[22] S. G. Varzaneh, M. Abedi, G. B. Gharehpetian, "A new simplified model for assessment of power variation of DFIG-based wind farm participating in frequency control system", Electric Power Systems Research, Vol. 148, pp. 220-229, 2017 
[23] S. Li, H. Wang, Y. Tian, A. Aitouch, J. Klein, "Direct power control of DFIG wind turbine systems based on an intelligent proportional-integral sliding mode control”, ISA Transactions, Vol. 64, pp. 431-439, 2016

[24] S. Louarem, S. Belkhiat, D. E. C. Belkhiat, "A Control Method using PI/Fuzzy Controllers Based-DFIG in Wind Energy Conversion System", 2013 IEEE PowerTech Grenoble, Grenoble, France, June 16-21, 2013

[25] R. Ata, "Artificial neural networks applications in wind energy systems: a review", Renewable and Sustainable Energy Reviews, Vol. 49, pp. 534-562, 2015

[26] M. Alberdi, M. Amundarain, A. Garrido, I. Garrido, "Neural control for voltage dips ride-through of oscillating water column-based wave energy converter equipped with doubly-fed induction generator", Renewable Energy, Vol. 48, pp. 16-26, 2012

[27] S. Skogestad, I. Postlethwaite, Multivariable Feedback Control: Analysis and Design, John Wiley \& Sons, 2007

[28] S. Khoete, Y. Manabe, M. Kurimoto, T. Funabashi, T. Kato, "Robust Hinfinity Control for DFIG to Enhance Transient Stability during Grid Faults", World Congress on Engineering and Computer Science, San Francisco, USA, October 19-26, 2016

[29] G. Duc, S. Font, Commande $\mathrm{H}_{\infty}$ et $\mu$ Analyse des Outils Pour la Robustesse, Hermes Science Publications, 1999 (in French)

[30] M. Brahim, I. Bahri, Y. Bernard, "Real time implementation of $\mathrm{H}$ infinity and RST motion control of rotary traveling wave ultrasonic motor", Mechatronics, Vol. 44, pp. 14-23, 2017

[31] Z. Y. Zhao, M. Tomizuka, S. Isaka, "Fuzzy Gain Scheduling of PID Controllers", The First IEEE Conference on Control Applications, Dayton, USA, September 13-16, 1992

[32] A. G. Aissaoui, A. Tahour, M. Abid, N. Essounbouli, F. Nollet, "A Fuzzy-PI control technique designed for Power Control of Wind Turbine based on Induction Generator", Advanced Materials Research, Vol. 875877, pp. 1676-1682, 2014 